\title{
The Research of Numerical Simulation about the Improved Dense Medium Cyclone
}

\author{
X.B. Li, Q.Q. Huang \\ School of Mechanical Engineering \\ Anhui University of Science and Technology \\ Huainan, Anhui, PR China
}

\author{
X. Li \\ College of Chemistry and Materials Science \\ South-Central University for Nationalities \\ Wuhan, Hubei, PR China
}

\begin{abstract}
The structure model, the CFD computing model and algorithm of flow field about the improved dense medium cyclone were analyzed in this paper. Then the simulation of flow field was done by using of CFD inside the improved dense medium cyclone. According to the simulation results, this paper analyzed the characteristics of the velocity field, the pressure field, the density field and the air column. The conclusion shows that the effect of medium separation and the distribution of flow field in the improved dense medium cyclone were improved obviously.
\end{abstract}

Keywords- dense medium cyclone; optimization of the structure; simulation of the flow field

\section{INTRODUCTION}

Dense medium cyclone has the advantages of simple structure and easy to design, but the flow field internal is a three-dimensional flow field of strong turbulence, the characteristics of the fluid motion is very complex. In order to study the process of dense medium cyclone coal preparation from the view of fluid mechanics, to explore the impact of structure and parameters on heavy medium separation process, all the countries especially the researchers coal power is studied on the separation process, and made some progress. The research results are as follows:

(1) The sorting process experiment. Analysis of the flow characteristics and separation process on heavy medium cyclone in theory, including the velocity of the fluid field, the centrifugal force field and the density field distribution and particles, and the effect of various parameters on the separation, by using the high speed camera and particle tracking display technology, and puts forward some new arguments[1].

(2) mathematical model. A mathematical model of dense medium cyclone was bulit though mass test data and theoretical analysis. The design parameters of dense medium cyclone much of them are obtained through the experiment of the dense medium cyclone, to determine the relationship between the corresponding condition of geometric parameters, operating parameters and performance based on the empirical formula of production practice, but the application of each experience model range is too small, so we get the correct parameters must rely on a large number of trials . L. R. Plitt, АЙЛораорв, D·A·Daimler, Xue-shi Pang, Liang-yin Chu and so on were systematically studied on cyclone and put forward different mathematic models[2].

(3)the numerical simulation of the flow field. Numerical simulation was conducted of local flow field in heavy medium cyclone by J.Bassman and N.Lournes. The paper presents an improved structure of cyclone Through the simulation results, unfortunately, the results of improvement is unknown in domestic[3]. The simulations with different degrees and the density distribution of heavy medium cyclone were did by M.S.Breanan [4].

Flow field of dense medium cyclone for multiphase flow numerical simulation by computer,

which make the research visualization, provides a foundation for optimization of parameters of dense medium cyclone and CFD could achieve these possible, computational fluid mechanics has been gradually show attractive prospects.

\section{STRUCTURE IMPROVEMENT AND MESH CyCLONE}

Life and the separation effect was effected by different inlet forms of dense medium cyclone. Tangent to the material is the most way of dense medium cyclone. Figure1 (a) the inside streamlines and the outer flow field of tangent entrance almost perpendicular intersection therefore, when the Medium into, the cyclone will produce a flow disturbance area where is located between the cyclone cylinder and the feed pipe to the overflow pipe junction. The pressure feeding of cyclone will increase the feeding short-circuit enters the overflow and affect the separation efficiency by. And the direction of motion changed rapidly when the outer streamline undercut, wall of tangent point area the large coal is intense impact, especially of waste rock with the density of hardness and high. The entrance wall will appear sunken, resulting in flow more chaos and complex flow and make the destruction process intensifies, resulting in a decline in the performance of cyclone by using this kind of cyclone for a long time.

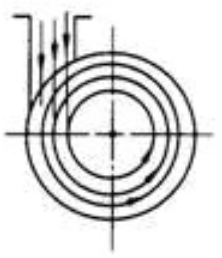

(a)

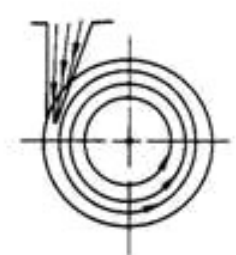

(b)

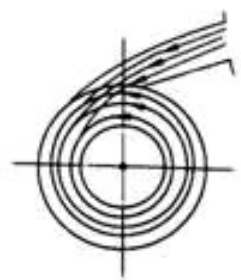

(c)
FIGURE I. DIFFERENT SKETCH OF INLET TUBE.

As Figure 1 (c), the number of intersecting angle of streamline reduced by cyclone spiral entrance or involute. This 
can reduce the impact of media on the wall and improve the disturbance of flow. Another benefit is that the feeding in the bent pipe of different density of the component will be a small part of the separation, density gradually moves toward the wall outside, equivalent to the pre separation of small scale, which on this can improve the separation efficiency of the cyclone, pro-long its service life. In the feeding pipe and anumber of areas, from the test [4] Liang-yin Chu concluded that the separation efficiency of two-way inlet cyclone is beter than that of the single inlet cyclone, and it also has low energy consumption.

The changes of structural parameters based on classical models of dense medium cyclone which is one of the widely used, remodeling, a model of cyclone center symmetric involute form of the double inlet is established in this paper.

First, find out the equation of involute, by driving the equation of a curve, drawing into a double involute material pipe in the Solidworks, and then save the parasolid.x_t* format, completed all the geometry modeling and grid in the Gambit.

In order to avoid continuity problems affect the analysis result, where the use of split mesh generating method. First to the 4 part of the whole into the cyclone, the upper half part of an overflow pipe, cylinder (a circular cylinder),barrel body,a conical section combination body and a feeding tube, 4 parts are used Hex/Wedge, hexahedral / wedge grid, the method of generation grid selection Cooper, the barrel type. down).

Figure2 is the new cyclone model in the grid map (looking

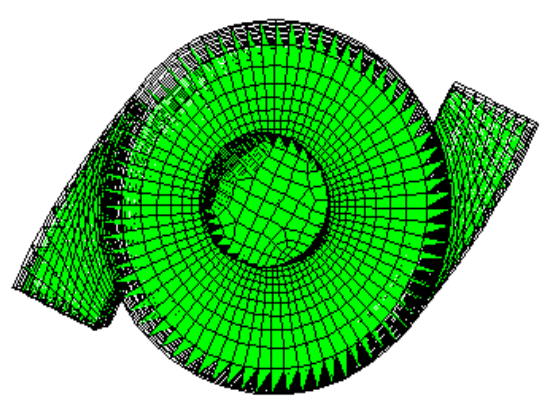

FIGURE II. MESH GIRD DISPLAY.

The geometric parameters of the new model as shown in Table 1.

TABLE I .IMPROVED DENSE MEDIUM CYCLONE.

\begin{tabular}{ccl}
\hline Structure parameters & unit & Numerical \\
\hline Cyclone diameter $\mathrm{D}$ & {$[\mathrm{mm}]$} & 800 \\
The length of cylinder $\mathrm{H}$ & {$[\mathrm{mm}]$} & 600 \\
The diameter of a feeding inlet $\mathrm{D}_{\mathrm{e}}$ & {$[\mathrm{mm}]$} & 210 \\
The diameter of overflow pipe $\mathrm{D}_{\mathrm{o}}$ & {$[\mathrm{mm}]$} & 180 \\
The diameter of underflow port $\mathrm{D}_{\mathrm{u}}$ & {$[\mathrm{mm}]$} & 200 \\
Cone angle & {$\left[{ }^{\circ}\right]$} & 22 \\
The depth of overflow tube insertion $\mathrm{h}$ & {$[\mathrm{mm}]$} & 300 \\
Inlet pressure $\mathrm{P}$ & {$[\mathrm{MPa}]$} & 0.13 \\
The inlet flow $\mathrm{Q}_{\mathrm{e}}$ & {$\left[\mathrm{m}^{3} / \mathrm{h}\right]$} & 400 \\
Overflow rate $\mathrm{Q}_{\mathrm{d}}$ & {$\left[\mathrm{m}^{3} / \mathrm{h}\right]$} & - \\
\hline
\end{tabular}

\section{SWIRLER SETTING BOUNDARY CONDITIONS}

\section{A. Inlet Conditions}

Inlet conditions are the choice of speed entrance, speed entrance can input many numerical information which were required for, associated with the cyclone model as follows:

(1) The relevant physical parameters of the medium components (Table 2);

(2)The medium into the cyclone: Including the components of the velocity ratio, volume ratio and the direction of the velocity;

(3)The turbulent situation of medium into the flow domain.

TABLE II MIXTURE PARAMETERS OF VARIOUS KINDS OF MEDIUM.

\begin{tabular}{|c|c|c|c|c|c|}
\hline Material & $\begin{array}{c}\text { Density } \\
/\left[\mathrm{kg}^{-3} \mathrm{~m}^{-3}\right. \\
\quad]\end{array}$ & $\begin{array}{c}\text { Viscos } \\
\text { ity } \\
/[\mathrm{Pa} \cdot \mathrm{m} \\
-3]\end{array}$ & $\begin{array}{l}\text { Particle } \\
\text { size/[m } \\
\text { m] }\end{array}$ & $\begin{array}{c}\text { Velocity } \\
\text { of the } \\
\text { entrance } \\
/\left[\mathbf{m} \cdot \mathbf{s}^{-1}\right]\end{array}$ & $\begin{array}{c}\text { The } \\
\text { volume } \\
\text { ratio of } \\
\text { the } \\
\text { entrance } \\
\%] \\
\end{array}$ \\
\hline $\begin{array}{l}\text { suspension } \\
\text { coal }\end{array}$ & $\begin{array}{l}1440 \\
1250\end{array}$ & $\underline{0.005}$ & $\overline{0.2 \sim 1}$ & $\begin{array}{l}10 \\
10\end{array}$ & $\begin{array}{l}82 \\
17\end{array}$ \\
\hline air & 1.02 & $\begin{array}{c}0.0000 \\
1\end{array}$ & 0.001 & 0 & 1 \\
\hline
\end{tabular}

The option settings Turbulence of submenu Momentum in the inlet speed. Choose the turbulent kinetic energy and turbulent dissipation in $\mathrm{k}-\varepsilon$ model and also can choose intensity and the hydraulic diameter.

\section{B. Exit Conditions}

Dense medium cyclone export to overflow and underflow port, two of exports are set to the boundary condition of Outflow, in outflow-top (overflow), the flow rate weighting column input 0.4 , then this parameter underflow port outflow-b is input 0.6 .

\section{Wall Conditions}

According to the requirements for simulation of cyclone, wall conditions do not have a separate settings, press the no slip boundary conditions, the default is a standard without heat exchange of the solid wall[5].

\section{SimUlation RESUltS AND ANALYSIS}

4 section selection of cyclone for section after treatment: $3 \mathrm{Z}$ axes (cyclone axial) section, a X axis (parallel to the axis of the inlet velocity) section; There are the axial cross section of Improved dense medium cyclone, $\mathrm{x}=0 \mathrm{~mm}$ (perpendicular to the direction of the inlet velocity the central shaft section); $z=2000 \mathrm{~mm}$ (the level surface beside the feed pipe).

\section{A. Velocity Distribution}

The following is the predicted velocity distribution. Figure 3 (a) is a mixture of the $\mathrm{x}=0 \mathrm{~mm}$ surface velocity distribution. Figure 3 (b) is the axial velocity distribution nephogram of shaft face. 


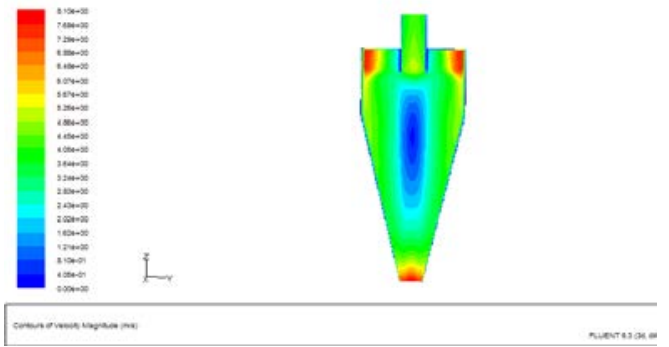

(a)

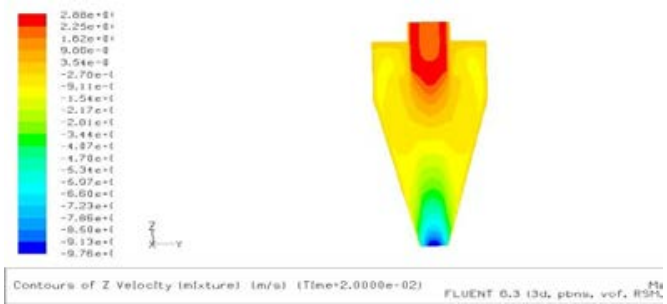

(b)

FIGURE III. THE VELOCITY DISTRIBUTION NEPHOGRAM OF SHAFT FACE.

\section{B. Pressure Distribution}

The total press of surface $\mathrm{X}=0 \mathrm{~mm}$ and $\mathrm{Z}=2000 \mathrm{~mm}$ are shown in Figure 4 (a), (b).

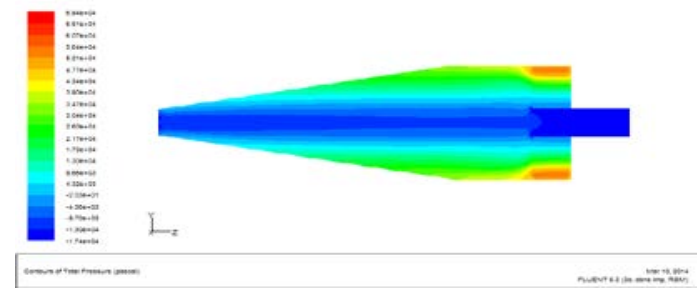

(a)

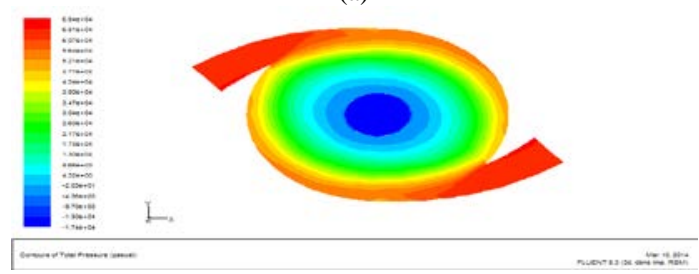

(b)

FIGURE IV. THE TOTAL PRESS ON THE SURFACES OF X=0MM AND $\mathrm{Z}=2000$.

\section{Density Distribution}
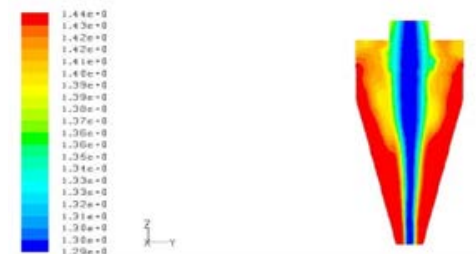

FIGURE V. IMPROVED DENSE MEDIUM CYCLONE AXIS SECTION CLOUD DENSITY DISTRIBUTION.

\section{The Air Column}

Air in the improved dense medium cyclone volume fraction distribution in shaft section is shown in Figure 6 (a) and air in the new cyclone volume fraction distribution $\mathrm{z}=2000 \mathrm{~mm}$ is shown in Figure 6 (b).

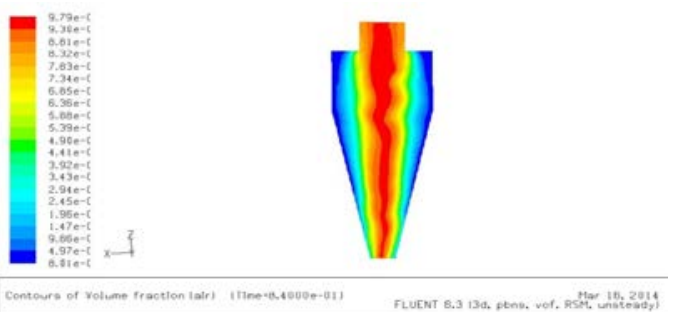

(a)

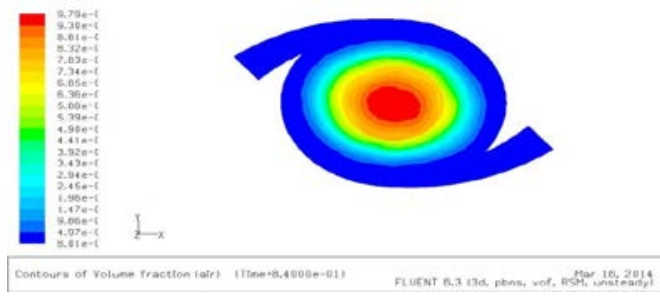

(b)

FIGURE VI. THE AIR VOLUME FRACTION DISTRIBUTION IN THE IMPROVED DENSE MEDIUM CYCLONE.

\section{CONCLUSION}

We get conclusion that the Improved dense medium cyclone inner velocity field, pressure field, density field and air column, Though the computer simulation of new model, analysis the simulation results of new model that conclusions are as follows:

(1)According to the simulation results on the velocity distribution of double inlet cyclone , the velocity distribution shows axial symmetry along the cyclone, the flow field distribution is more symmetrical balance, but also can obtain the larger axial velocity.

(2)Based on the simulation results on pressure of double inlet cyclone model , the pressure distribution is very uniform, almost central symmetric perfect, stable pressure field helps to improve separation efficiency.

Seen from Figure5, the simulation results of the double inlet cyclone show that the density distribution inside the cyclone is basically symmetrical, suspension density is big can with high density of coarse coal to underflow, overflow pipe of coal flow.

(3)The double inlet involute channel, its effect is very obvious, the flow field is stable after the medium entering the cyclone in a very short period of time, it terminate the iteration in the Time $=8.4000 \mathrm{e}-01$, the medium formed the air column through the underflow and the overflow pipe

when the medium into the cyclone after 0.84 seconds. 


\section{REFERENCES}

[1] Feng Liu, Ai-jun Qian. CFD simulation of flow field in dense medium cyclone [J]. Coal Preparation Technology, 2004(5):10 15.

[2] Ai-jun Qian. Numerical simulation of flow field of heavy medium cyclone [D].Tangshan: Tangshan branch of Coal Science Research Institute, 2004.

[3] Shao-lei Zhou, Hong Wang. High efficient coal preparation of new technology and new equipment[M], China University of Mining and Technology press,2008.

[4] Liang-yin Chu, Wen-mei Chen. Cyclone[M]. Chemical Industry Press,1998.

[5] Anderson D A, Tannehill J C, Pletcher R H. Computational fluid mechanical and heat transfer[M].Washington DC:Hemisphere,1984:1999 2001. 